\title{
Validation Analysis Methods of $\alpha$-Mangostin, $\Upsilon$-Mangostin and Gartanin Mixture in Mangosteen (Garcinia mangostana L.) Fruit Rind Extract from West Java with HPLC
}

\author{
Muchtaridi Muchtaridi $^{1 *}$, Nadia Ananda Puteri ${ }^{1}$, Tiana Milanda ${ }^{2}$, Ida Musfiroh ${ }^{1}$ \\ ${ }^{1}$ Department of Pharmaceutical Analysis and Medicinal Chemistry, Faculty of Pharmacy Universitas Padjadjaran, Sumedang, Indonesia. \\ ${ }^{2}$ Department of Pharmacology and Biology Pharmacy, Faculty of Pharmacy Universitas Padjadjaran, Sumedang, Indonesia.
}

\section{ARTICLE INFO}

Article history:

Received on: 25/05/2017

Accepted on: 09/08/2017

Available online: $30 / 10 / 2017$

\section{Key words:}

$\alpha$-mangostin, $\gamma$-mangostin, gartanin, HPLC, Solid Phase Extraction (SPE).

\begin{abstract}
The quantitative analysis methods for bioactive compounds in mangosteen pericarp have been reported. The purpose of this study is to validate the methods of analysis for $\alpha$-mangostin, $\gamma$-mangostin, and gartanin in mangosteen rind extract derived from Bogor, Purwakarta, Subang and Tasikmalaya using High Performance Liquid Chromatography (HPLC) for routine analysis. The methods employed were Enduro C-18 reverse-phase $(250 \mathrm{~mm} \times 4.6 \mathrm{~mm})$ column chromatography systems with Photo Diode Array detector $375 \mathrm{~nm}$ and acetonitrile: water containing $0.1 \%$ phosphoric acid (95:5) as the mobile phase at the flow rate of $1.0 \mathrm{~mL} / \mathrm{min}$ and validation methods with parameters of linearity, limit of detection and quantification, precision, and accuracy. Mangosteen rind extracts were pre-treated with the technique of solid-phase extraction (SPE). The results of this study show that the validation results meet the requirements of the standard retention time of $\alpha$-mangostin at 5.801 minutes, $\gamma$-mangostin at 4.707 minutes and gartanin at 5.290 minutes. The correlation coefficient (R) for each standard were $0.999,0.999$, and 0.999 , respectively. The value of recovery for the $\alpha$-mangostin, $\gamma$-mangostin, and gartanin were $100.32 \%, 102.31 \%$, and $101.48 \%$, respectively. The analysis shows that the levels of $\alpha-$ mangostin, $\gamma$-mangostin, and gartanin from Bogor are $13.87 \%, 8.28 \%$ and $10.44 \%$, respectively. The results from mangosteen pericarp extract from Purwakarta are $10.07 \%$ for $\alpha$-mangostin, $6.33 \%$ for $\gamma$-mangostin, and $8.76 \%$ gartanin. Mangosteen pericarp extract from Subang has concentrations of $\alpha$-mangostin at $10.88 \%, \gamma$ mangostin at $6.01 \%$, and gartanin at $8.08 \%$. The contents of $\alpha$-mangostin, $\gamma$-mangostin, and gartanin from Tasikmalaya are $8.53 \%, 6.07 \%, 17.28 \%$ respectively. This study concludes that the methods are valid and can be used for routine analysis.
\end{abstract}

\section{INTRODUCTION}

Mangosteen (Garcinia mangostana L.) as a tropical queen of fruits has become one of the Indonesian important export commodities because of its sweet-sour and pleasant taste. Fruit rinds which become waste, are usually used as traditional medicine in Thailand to alleviate diarrhoea or treatment for skin

\footnotetext{
* Corresponding Author

Muchtaridi Muchtaridi, Department of Pharmaceutical Analysis and Medicinal Chemistry, Faculty of Pharmacy UniversitasPadjadjaran, Jl. Bandung-Sumedang KM-21, 45363, Jatinangor, Indonesia. E-mail: muchtaridi @unpad.ac.id
}

infection and wounds (Pothitirat et al., 2009). Many compounds have been reported to be isolated from G. mangostana rind extract, such as: $\alpha$-mangostin, gartanin, $\gamma$-mangostin, 3-isomangostin (Walker, 2007; Mahabusarakam et al., 1987). These isolated xanthones provide diverse pharmacological uses such as antimicrobial, antimalarial, antioxidant, and anti-inflammatory functions (Iinuma et al., 1996; Mahabusarakam et al., 2006; Mahabusarakam et al., 2000; Chen et al., 2008). In the current study, xanthones of mangosteen have inhibitory effects against neuraminidase of $C$. perferingens (Ryu et al., 2010). The number of studies to determine valid analytical methods to identify xanthone derivatives are still lower than those in isolating xanthone compounds (Walker, 2007). 
Some studies in analytical methods for the determination of xanthones in extracts of mangosteen pericarp have been performed as reported in some literatures (Yodhnu et al., 2009; Walker, 2007; Li et al., 2013). The development in analytical methods ensure that the methods used are valid and replicable. Validation methods of simultaneous determination of compound contained in Garcinia mangostana rind extract also facilitate methods to specify more than one compound in mixtures samples.

\section{MATERIALS AND METHODS}

\section{Chemicals}

The standard xanthones ( $\alpha$-mangostin, gartanin and $\gamma$-mangostin) used as references were purchased from Chengdu Biopurified, China. The solvents are HPLC grade, acquired from JT Baker ${ }^{\circledR}$.

\section{Plant material and extraction}

Mangosteen rinds obtained from Bogor, Purwakarta, Tasikmalaya, and Subang (West Java, Indonesia) were identified by Drs. Joko Kusmoro, MS., a scientist in Department of Biology, the Faculty of Mathematics and Natural Sciences. Samples were cleaned, cut, air-dried, and finally powdered. Fruit rinds were extracted by maceration using $900 \mathrm{~mL}$ of $70 \%$ ethanol for 72 hours. The extract was dried in an oven at $40{ }^{\circ} \mathrm{C}$.

\section{UV Spectral Analysis}

Standard mixture consisting of $\alpha$-mangostin, $\gamma$-mangostin and gartanin are diluted into three concentrations. Concentrations used for $\alpha$-mangostin are 2.5, 5 and $10 \mathrm{ppm}$; for $\gamma$-mangostin are 20, 40, and $80 \mathrm{ppm}$; and for gartanin are 10, 20, and $40 \mathrm{ppm}$. Each standard was analyzed with UV Spectroscopy. UV spectra collected from UV spectrophotometer (Analytikjena specord $200^{\circledR}$ ) and performed in range 200-400 $\mathrm{nm}$ resulting $375 \mathrm{~nm}$ for chromatograms.

\section{Preparation of standard mixture}

Stock solution of the standard mixture consisting of $\alpha$ mangostin, $\gamma$-mangostin and gartanin was prepared at $2 \mathrm{mg} / \mathrm{mL}$ in HPLC grade methanol. The solution was further diluted to obtain $200,100,25,10$, and $5 \mu \mathrm{g} / \mathrm{mL}$. The sample extracts were prepared at $500 \mu \mathrm{g} / \mathrm{mL}$ in the same solvent, and were further diluted to obtain $100 \mu \mathrm{g} / \mathrm{mL}$. The stock solutions were filtered through 0.45 $\mu \mathrm{m}$ syringe filters.

\section{Preparation of Samples}

Pre-treatments were conducted to extract samples with Solid Phase Extraction (SPE) to obtain $\pm 92.50 \%$ recovery. Samples are diluted into methanol to $100 \mu \mathrm{g} / \mathrm{mL}$, followed by SPE processes with C-18 cartridges $47 \mathrm{~mm}$ Supor ${ }^{\circledR}-450$ membrane purchased from Pall Corp (Michigan, US). SPE processes include conditioning them with $1 \mathrm{~mL}$ of methanol, sample loading (diluting extract to $100 \mathrm{ppm}, 1 \mathrm{~mL}$ ), washing them with 1 $\mathrm{mL}$ of double-distilled water, and eluting them with methanol.

\section{RESULTS AND DISCUSSIONS}

\section{Validation Methods}

System suitability such as column efficiency, resolution, plate number, and tailing factor are applied to ensure that the HPLC system is capable of providing adequate data for analysis (Ermer, 2001; Ermer and Ploss, 2005). Plate number, resolution, tailing factor, and column efficiency are parameters in this study set to carry out analysis as shown in Table 1. According to Table 1 , the suitability of system has met the requirements. We further analyzed the linearity of methods using five concentration variation: $5 ; 10 ; 20 ; 40$; and $80 \mu \mathrm{g} / \mathrm{mL}$. Each variation is injected into HPLC with three replications thus producing coefficient correlation value for $\alpha$-mangostin, $\gamma$-mangostin, and gartanin of $0.999,0.999$, and 0.999 , respectively. All of the values which exceed the value of coefficient correlation of 0.99 was valid $(\mathrm{ICH}$, 1996) (as shown in Figure 1).

Table 1: Results of parameters of system suitability experiments.

\begin{tabular}{ccccccc}
\hline & $\begin{array}{c}\text { Retention } \\
\text { Time }\end{array}$ & $\begin{array}{c}\text { N (Plate } \\
\text { Number) }\end{array}$ & $\begin{array}{c}\text { HETP } \\
(\mathbf{L} / \mathbf{N})\end{array}$ & $\begin{array}{c}\text { Tailing } \\
\text { factor }\end{array}$ & k' & Rs \\
\hline$\alpha$-mangostin & 5.805 & $15,385.92$ & 0.016 & 0.032 & 0.871 & 10.74 \\
$\gamma$-mangostin & 4.707 & $15,385.92$ & 0.016 & 0.031 & 0.517 & 6.40 \\
Gartanin & 5.290 & $15,385.92$ & 0.016 & 0.011 & 0.705 & 13.467 \\
\hline
\end{tabular}

* L $=$ HPLC Column Length $(25 \mathrm{~cm})$

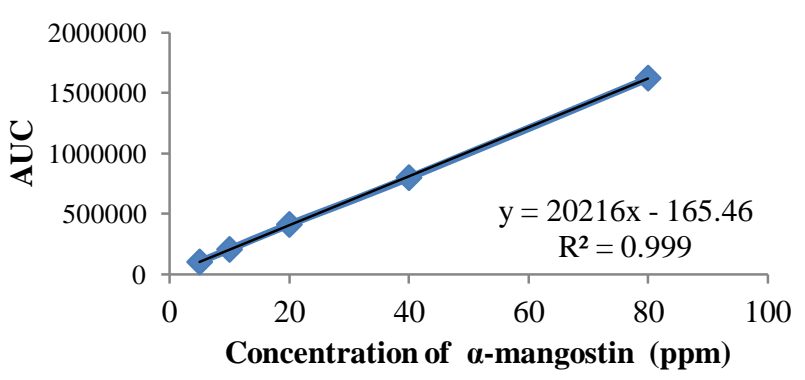

A

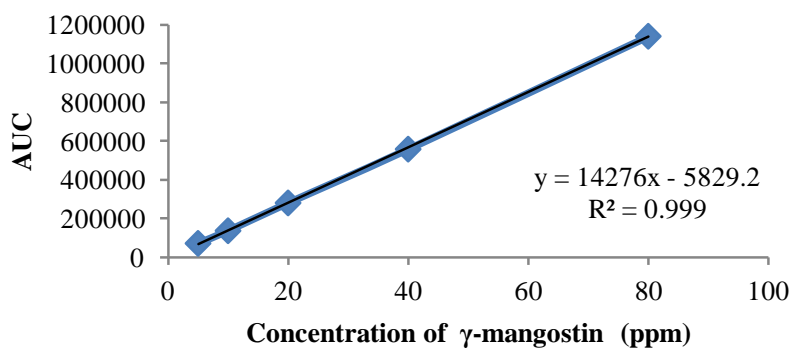

B

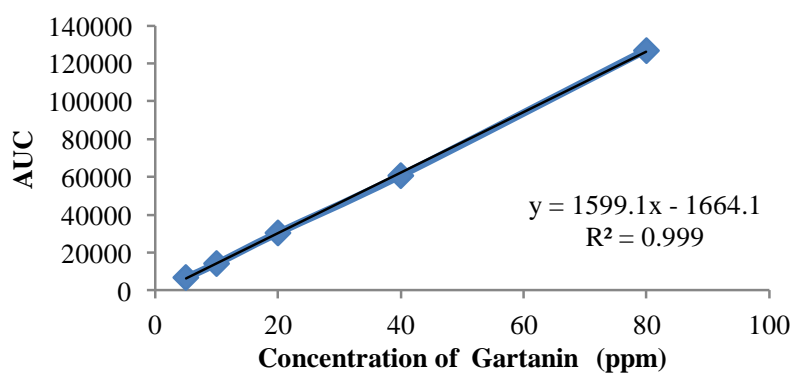

Fig. 1: Calibration curve of $\gamma$-mangostin (a), $\alpha$-mangostin (b), and gartanin (c). 
Table 2: Accuracy of $\alpha$-mangostin, $\gamma$-mangostin, Gartanin.

A- Accuracy of $\gamma$-mangostin.

\begin{tabular}{ccccc}
\hline $\begin{array}{c}\text { Concentra } \\
\text { tion(ppm) }\end{array}$ & AUC & $\begin{array}{c}\text { Measured } \\
\text { Concentration } \\
\text { (ppm) }\end{array}$ & $\begin{array}{c}\text { \% } \\
\text { Recovery }\end{array}$ & $\begin{array}{c}\text { \% Average } \\
\text { of } \\
\text { Recovery }\end{array}$ \\
\hline $\mathbf{5}$ & 100,226 & 4.965 & 99.318 & \\
$\mathbf{5}$ & 97,963 & 4.979 & 99.583 & 100.63 \\
$\mathbf{5}$ & 105,406 & 5.149 & 102.989 & \\
$\mathbf{1 0}$ & 203,854 & 10.091 & 100.919 & \\
$\mathbf{1 0}$ & 209,237 & 10.221 & 102.210 & 101.54 \\
$\mathbf{1 0}$ & 210,801 & 10.148 & 101.483 & \\
$\mathbf{2 0}$ & 410,185 & 20.298 & 101.491 & \\
$\mathbf{2 0}$ & 414,588 & 19.894 & 99.473 & 100.17 \\
$\mathbf{2 0}$ & 416,538 & 19.906 & 99.531 & \\
$\mathbf{4 0}$ & 797,421 & 39.453 & 98.633 & \\
$\mathbf{4 0}$ & 837,319 & 39.808 & 99.521 & 99.05 \\
$\mathbf{4 0}$ & 831,765 & 39.600 & 99.000 & \\
$\mathbf{8 0}$ & $1,620,895$ & 80.187 & 100.233 & \\
$\mathbf{8 0}$ & $1,692,494$ & 80.093 & 100.117 & 100.20 \\
$\mathbf{8 0}$ & $1,687,662$ & 80.194 & 100.243 & \\
\hline
\end{tabular}

\begin{tabular}{ccccc} 
B- & Accuracy of $\gamma$-mangostin. & & \\
\hline $\begin{array}{c}\text { Concentra } \\
\text { tion }\end{array}$ & AUC & $\begin{array}{c}\text { Measured } \\
\text { conc. } \\
\text { (ppm) }\end{array}$ & $\begin{array}{c}\text { \% } \\
\text { Recovery }\end{array}$ & $\begin{array}{c}\text { \% Average } \\
\text { of Recovery }\end{array}$ \\
\hline $\mathbf{5}$ & 68,4481 & 5.202 & 104.058 & \\
$\mathbf{5}$ & 63,025 & 4.823 & 96.461 & 99.88 \\
$\mathbf{5}$ & 70,211 & 4.955 & 99.108 & \\
$\mathbf{1 0}$ & 136,019 & 9.936 & 99.361 & \\
$\mathbf{1 0}$ & 141,635 & 10.329 & 103.295 & 101.28 \\
$\mathbf{1 0}$ & 147,712 & 10.118 & 101.180 & \\
$\mathbf{2 0}$ & 279,612 & 19.994 & 99.972 & \\
$\mathbf{2 0}$ & 284,346 & 20.326 & 101.630 & 99.77 \\
$\mathbf{2 0}$ & 289,146 & 19.539 & 97.697 & \\
$\mathbf{4 0}$ & 557,220 & 39.440 & 98.600 & \\
$\mathbf{4 0}$ & 593,747 & 41.998 & 104.997 & 100.56 \\
$\mathbf{4 0}$ & 584,860 & 39.237 & 98.094 & \\
$\mathbf{8 0}$ & $1,140,105$ & 80.269 & 100.337 & \\
$\mathbf{8 0}$ & $1,215,064$ & 85.520 & 106.900 & 102.60 \\
$\mathbf{8 0}$ & $1,203,380$ & 80.439 & 100.549 & \\
\hline
\end{tabular}

C- Accuracy of Gartanin.

\begin{tabular}{ccccc}
\hline $\begin{array}{c}\text { Concentration } \\
\text { (ppm) }\end{array}$ & $\begin{array}{c}\text { Area } \\
\text { (AUC) }\end{array}$ & $\begin{array}{c}\text { Measured } \\
\text { conc. }(\mathbf{p p m})\end{array}$ & $\begin{array}{c}\text { \% } \\
\text { Recovery }\end{array}$ & $\begin{array}{c}\text { \% Average } \\
\text { of Recovery }\end{array}$ \\
\hline $\mathbf{5}$ & 6,329 & 4.998 & 99.997 & \\
$\mathbf{5}$ & 6,543 & 5.132 & 101.603 & 102.52 \\
$\mathbf{5}$ & 6,812 & 5.301 & 106.010 & \\
$\mathbf{1 0}$ & 14,334 & 10.004 & 100.044 & \\
$\mathbf{1 0}$ & 16,071 & 10.564 & 105.649 & 100.97 \\
$\mathbf{1 0}$ & 15,848 & 9.720 & 97.204 & \\
$\mathbf{2 0}$ & 30,535 & 20.135 & 100.678 & \\
$\mathbf{2 0}$ & 30,891 & 18.902 & 94.510 & 97.82 \\
$\mathbf{2 0}$ & 33,515 & 19.652 & 98.262 & \\
$\mathbf{4 0}$ & 60,802 & 39.063 & 97.658 & \\
$\mathbf{4 0}$ & 67,627 & 39.568 & 98.920 & 99.04 \\
$\mathbf{4 0}$ & 70,086 & 40.211 & 100.529 & \\
$\mathbf{8 0}$ & 126,917 & 80.408 & 100.510 & \\
$\mathbf{8 0}$ & 140,176 & 80.381 & 100.476 & 100.32 \\
$\mathbf{8 0}$ & 140,838 & 79.986 & 99.983 & \\
\hline
\end{tabular}

Accuracy of $\alpha$-mangostin, $\gamma$-mangostin, and gartanin were studied at concentration of $5,10,20,40$ and $80 \mu \mathrm{g} / \mathrm{mL}$ of each individual reference compound. The accuracy ranges between 90 and110\% with results presented in average \pm SD $(n=3)$. Accuracy results show a range between 99.05 and $101.54 \%$ for $\alpha$ mangostin, 99.77and $99.98 \%$ for $\gamma$-mangostin, and 97.82 and $99.98 \%$ for gartanin which comply with the validation qualification in the range from 80 to $110 \%$ for accuracy in unit concentration ranging from 1 to 10 ppm measured, and 90-107\% for accuracy in unit concentration from 10 to $100 \mathrm{ppm}$ measured (AOAC, 2002). The percentages of variation coefficient were measured for the precision analysis which considered retention time and peak area of the curves. The standard mixture was analyzed at a concentration of $20 \mu \mathrm{g} / \mathrm{mL}(\mathrm{n}=6)$. Precision results indicated good reproducibility. The results of precision in method validation for $\alpha$-mangostin, $\gamma$-mangostin, and gartanin based on AUC stated as RSD (\%) were 1.591\%, 1.663\%, and 1.912\%, respectively. Based on retention time, the results of variation coefficient were $0.596 \%, 0.439 \%$, and $0.393 \%$ for $\alpha$-mangostin, $\gamma$ mangostin, and gartanin consecutively. The precision was determined based on the Limit of Detection (LOD) and the Limit of Quantification (LOQ).

Table 3: Precision method validation of $\alpha$-mangostin (A), $\gamma$-mangostin (B), Gartanin (C).

\begin{tabular}{ccc}
$\begin{array}{c}\text { A- } \quad \boldsymbol{\alpha} \text {-mangostin. } \\
\begin{array}{c}\text { Concentration } \\
\text { (ppm) }\end{array}\end{array}$ & AUC & $\begin{array}{c}\text { Retention Time } \\
\text { (minutes) }\end{array}$ \\
\hline 20 & 148,427 & 5.767 \\
20 & 145,992 & 5.838 \\
20 & 143,025 & 5.817 \\
20 & 145,276 & 5.829 \\
20 & 149,587 & 5.752 \\
20 & 146,138 & 5.806 \\
Total & 878,445 & 34.809 \\
Average & $146,407.5$ & 5.801 \\
SD & $2,330.428$ & 0.034 \\
\%RSD & 1.592 & 0.597 \\
\hline
\end{tabular}

\begin{tabular}{ccc}
$\begin{array}{c}\text { B- } \boldsymbol{\gamma} \text {-mangostin. } \\
\begin{array}{c}\text { Concentration } \\
\text { (ppm) }\end{array}\end{array}$ & AUC & $\begin{array}{c}\text { Retention Time } \\
\text { (minutes) }\end{array}$ \\
\hline 20 & 148,427 & 4.687 \\
20 & 145,992 & 4.731 \\
20 & 143,025 & 4.715 \\
20 & 145,276 & 4.723 \\
20 & 149,587 & 4.678 \\
20 & 146,138 & 4.708 \\
Total & $1,302,569$ & 28.242 \\
Average & $217,094.8$ & 4.707 \\
SD & 3611.359 & 0.020 \\
$\%$ RSD & 1.663 & 0.439 \\
C- & & \\
Gartanin. & & Retention Time \\
Concentration & AUC & (minutes) \\
(ppm) & 16,584 & 5.272 \\
20 & 16,926 & 5.315 \\
20 & 16,100 & 5.302 \\
20 & 16,286 & 5.303 \\
20 & 16,187 & 5.26 \\
20 & 16,628 & 5.292 \\
20 & 98,711 & 31.744 \\
Total & $16,451.83$ & 5.290 \\
Average & 314.566 & 0.020 \\
SD & 1.912 & 0.393 \\
$\%$ RSD & &
\end{tabular}

LOD and LOQ are calculated to analyze the amount of $\alpha$ mangostin, $\gamma$-mangostin and gartanin in mangosteen rind extract statistically calculated based on the equation of the calibration curve to the area under the peak area ratio. In method validation the values of LOD and LOQ are important in terms of characteristics. The values of $\alpha$-mangostin were $0.161 \mathrm{ppm}$ and 
$0.488 \mathrm{ppm}, \gamma$-mangostin $0.013 \mathrm{ppm}$ and $0.039 \mathrm{ppm}$, and gartanin $0.019 \mathrm{ppm} 5$ and $0.060 \mathrm{ppm}$. These results are better than those in the previous analysis which obtained higher LOD and LOQ for $\alpha$ mangostin (Popp et al., 2000).

\section{Results of $\alpha$-mangostin, $\gamma$-mangostin and Gartanin Analysis in} Mangosteen Rind Extract of Four Districts in West Java

Mangosteen pericarp extracts are given SPE pretreatment which mainly distinguishes analytes in a complex matrix by the differences of hydrophobicity. The SPE technique has been used successfully for separating organic compounds from complex samples (Zhang et al., 2016; Otles and Kartal, 2016).

C-18 cartridges are used for hydrophobic (strongly nonpolar) types of analyte . Each step of the SPE pre-treatment required a solvent matching the hydrophobic analyte type.
For the eluting solvent, methanol may be used with intermediate polarity (Muchtaridi and Musfiroh, 2012). Mangosteen pericarp extract which has been given SPE pre-treatment and eluted with methanol is injected to an HPLC instrumentation with a validated condition. Chromatogram results were obtained and the concentration of $\alpha$-mangostin, $\gamma$-mangostin and gartanin are calculated by Area Under Curve (AUC) at each standard retention time. The analysis showed that the levels of $\alpha$-mangostin, $\gamma$ mangostin, and gartanin from Bogor respectively are $13.87 \%$, $8.28 \%$ and $10.44 \%$. The results for mangosteen pericarp extract from Purwakarta are $10.072 \%$ for $\alpha$-mangostin, $6.33 \%$ for $\gamma$ mangostin, and $8.77 \%$ for gartanin. The resuts for mangosteen pericarp extract from Subang are $10.88 \%$ for $\alpha$-mangostin, $6.012 \%$ for $\gamma$-mangostin, and $8.54 \%$ for gartanin. Lastly, the $\alpha$-mangostin, $\gamma$-mangostin, and gartanin contents of pericarp extracts from Tasikmalaya are $8.53 \%, 6.07 \%$, and $8.64 \%$, respectively.
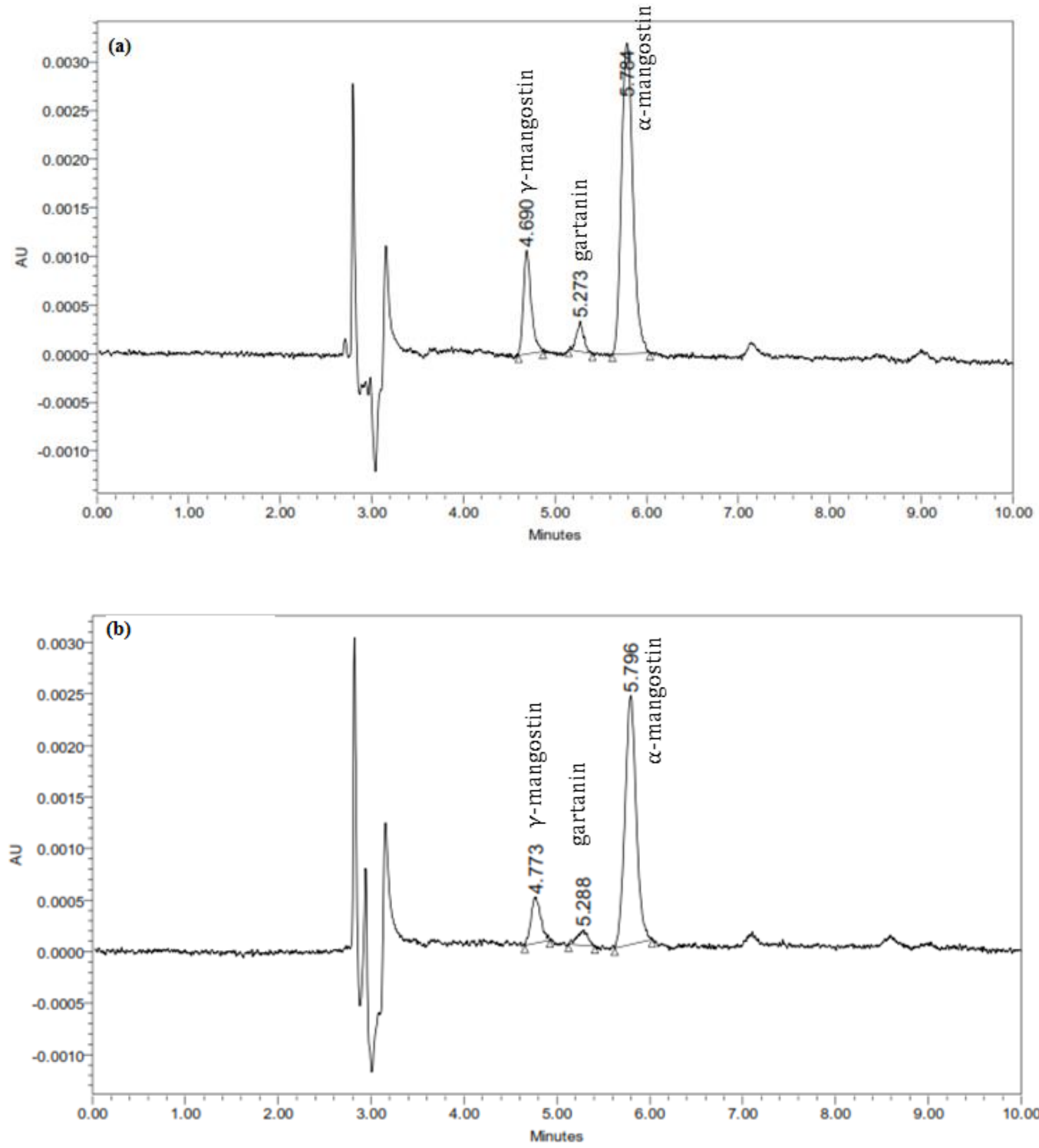

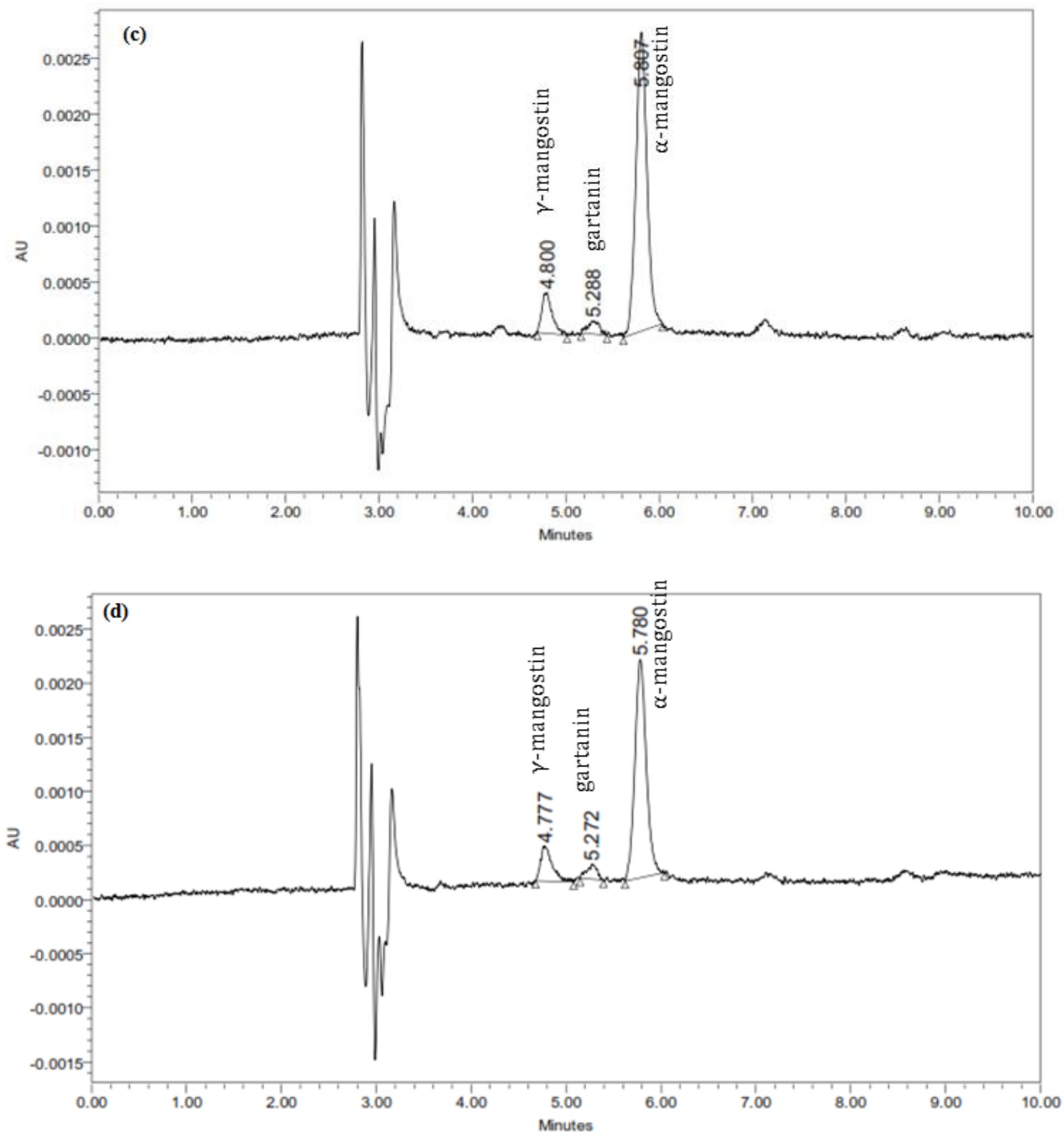

Fig. 2: Chromatograms of mangosteen rind extracts from Bogor (a), Purwakarta (b), Subang (c), and Tasikmalaya.

\section{CONCLUSION}

These results showed that this HPLC method can be used for routine analysis of $\alpha$-mangostin, $\gamma$-mangostin and gartanin from mangosteen. The optimum condition was performed using Enduro column C-18 reverse phase (250 mm x $4.6 \mathrm{~mm}$ ), Photo Diode Array detector $375 \mathrm{~nm}$, acetonitrile mobile phase and water containing $0.1 \%$ phosphoric acid (95: 5) with a flow rate of 1.0 $\mathrm{mL} / \mathrm{min}$.

\section{ACKNOWLEDGEMENT}

The authors are thankful to Basic Science Research Centre and Pharmaceutical Analysis and Medicinal Chemistry laboratory (Faculty of Pharmacy), Universitas Padjadjaran and the Ministry Research, Technology, and Higher Education of Indonesia for providing the necessary facilities for the research.
Financial support and sponsorship: Penelitian Unggulan Perguruan Tinggi (PUPT) 2017 for financial support.

Conflict of Interests: There are no conflicts of interest.

\section{REFERENCES}

AOAC International. AOAC Guidelines for Single Laboratory Validation of Chemical Methods for Dietary Supplements and Botanicals, Arlington, VA. Available from http://www.aoac.org/Official_Methods/slv_guidelines.pdf, 2002.

Chen, LG, Yang, LL, and Wang, CC. Anti-inflammatory activity of mangostins from Garcinia mangostana. Food Chem Toxicol, 2008; 46 (2): 688-693.

Ermer, J. Validation in pharmaceutical analysis. Part I: an integrated approach. J Pharm Biomed Anal, 2001; 24 (5-6): 755-767.

Ermer, J, and Ploss, HJ. Validation in pharmaceutical analysis. Part II: Central importance of precision to establish acceptance criteria and 
for verifying and improving the quality of analytical data. J Pharm Biomed Anal, 2005; 37 (5): 859-870.

ICH, I. Validation of Analytical Procedures: Methodology. Q2b, edited by F. R. FDA. New York: FDA,1996; 11260.

Iinuma, M, Tosa, H, Tanaka, T, Asai, F, Kobayashi, Y, Shimano, R, and Miyauchi, K. Antibacterial activity of xanthones from guttiferaeous plants against methicillin-resistant Staphylococcus aureus. J Pharm Pharmacol, 1996; 48 (8): 861-865.

Li, L, Han, AR, Kinghorn, AD, Frye, RF, Derendorf, H, and Butterweck, V. Pharmacokinetic properties of pure xanthones in comparison to a mangosteen fruit extract in rats. Planta Med, 2013; 79 (8): 646-653.

Mahabusarakam, W, Kuaha, K, Wilairat, P, and Taylor, WC. Prenylated xanthones as potential antiplasmodial substances. Planta Med, 2006; 72 (10): 912-916.

Mahabusarakam, W, Proudfoot, J, Taylor, W, and Croft, K. Inhibition of lipoprotein oxidation by prenylated xanthones derived from mangostin. Free Radic Res, 2000; 33 (5): 643-659.

Mahabusarakam, W, Wiriyachitra, P, and Taylor, WC. Chemical Constituents of Garcinia mangostana. Journal of Natural Products, 1987; 50 (3): 474-478.

Muchtaridi, M, and Musfiroh, I. Off-Line SPE-GC/MS Analysis of Lead Compounds Aromatherapy in Blood Plasma of Mice of Essential Oils Materials from Indonesian Aromatic Plants. Asian J. Chem., 2012; 24 (11): 5124

Otles, S, and Kartal, C. Solid-Phase Extraction (SPE): Principles and Applications in Food Samples. Acta Sci Pol Technol Aliment, 2016; 15 (1): 5-15

Popp, P, Bauer, C, Moder, M, and Paschke, A. Determination of polycyclic aromatic hydrocarbons in waste water by off-line coupling of solid-phase microextraction with column liquid chromatography. J Chromatogr A, 2000; 897 (1-2): 153-159.
Pothitirat, W, Chomnawang, MT, Supabphol, R, and Gritsanapan, W. Comparison of bioactive compounds content, free radical scavenging and anti-acne inducing bacteria activities of extracts from the mangosteen fruit rind at two stages of maturity. Fitoterapia, 2009; 80 (7): 442-447.

Ryu, HW, Curtis-Long, MJ, Jung, S, Jin, YM, Cho, JK, Ryu, YB, Lee, WS, and Park, KH. Xanthones with neuraminidase inhibitory activity from the seedcases of Garcinia mangostana. Bioorganic \&amp; Medicinal Chemistry, 2010; 18 (17): 6258-6264.

Walker, EB. HPLC analysis of selected xanthones in mangosteen fruit. J Sep Sci, 2007; 30 (9): 1229-1234.

Yodhnu, S, Sirikatitham, A, and Wattanapiromsakul, C. Validation of LC for the determination of alpha-mangostin in mangosteen peel extract: a tool for quality assessment of Garcinia mangostana L. J Chromatogr Sci, 2009; 47 (3): 185-189.

Zhang, Q, Zhou, L, Chen, H, Wang, CZ, Xia, Z, and Yuan, CS. Solid-phase microextraction technology for in vitro and in vivo metabolite analysis. Trends Analyt Chem, 2016; 80: 57-65.

\section{How to cite this article:}

Muchtaridi M, Puteri NA, Milanda T, Musfiroh I. Validation Analysis Methods of A-Mangostin, Г-Mangostin, AndGartanin Mixture in Mangosteen (Garcinia mangostana L.) Fruit Rind Extract from West Java with HPLC. J App Pharm Sci, 2017; 7 (10): 125-130. 